\section{Introductory Biology in Social Context: The Effects of an Issues-Based Laboratory Course on Biology Student Motivation}

\author{
Krissi M. Hewitt, ${ }^{\dagger}$ Jana Bouwma-Gearhart, ${ }^{\dagger}$ Heather Kitada, ${ }^{\S}$ Robert Mason," \\ and Lori J. Kayes"** \\ †Office of Research, Planning and Assessment, North Carolina School of Science and \\ Mathematics, Durham, NC 27705; `College of Education and "Department of Integrative \\ Biology, Oregon State University, Corvallis, OR 97331; \$Mathematics Department, Reed College, \\ Portland, OR 97202
}

\begin{abstract}
We investigated the effects of a laboratory curriculum developed using the socio-scientific issues (SSI) framework to contextualize scientific and socially relevant issues for students. Using self-determination theory and hierarchical linear modeling, we examined the effects of the SSI curriculum relative to a control curriculum on student motivation in a large introductory biology course for life science majors. The SSI group had a significant increase in motivation for engaging in the laboratory work relative to motivation of the control group. Additionally, the SSI group showed higher levels of more autonomous forms of regulation concerning participation in laboratory tasks compared with the control group. Interestingly, the SSI-based curriculum seemed to have a buffering effect on typically observed decreases in student motivation over the course of a term. This buffering effect could potentially indicate greater self-determination in students experiencing an SSI-based curriculum, which could lead to greater student success and persistence. Qualitative data suggest that this increased motivation of the SSI group relative to the control group is due to enhanced feelings of relatedness experienced by students, likely due to the SSI.
\end{abstract}

\section{INTRODUCTION}

Recent advancements in the biological sciences have resulted in a large number of social, political, and technological issues that require action from both scientists and citizens (e.g., genetic modification of foods; American Association for the Advancement of Science [AAAS], 1989, 2011). These issues have led to an increasing demand on postsecondary educators to help develop citizens who are biologically literate (AAAS, 2011; Hall et al., 2011). Functional biological literacy is an active form of scientific literacy indicated by an individual's ability to read about, comprehend, communicate, and form opinions about biological issues (Laugksch, 2000). While formal education experiences can be put in place to help foster these skills, research indicates that typical postsecondary biology education experiences tend to focus on rote memorization of facts and concepts devoid of social context (Seymour and Hewitt, 1997; AAAS, 2011). Transformation of curricula and instruction to incorporate activities that engage students in authentic scientific practices and the application of these practices to real-world problems (Barab and Plucker, 2002; Chamany et al., 2008) is needed in postsecondary biology classrooms.

\section{Socio-Scientific Issues-Based Instruction}

One pedagogical approach that may help meet these goals is a socio-scientific issuesbased approach (Zeidler et al., 2005; Sadler et al., 2007; Lenz and Willcox, 2012). Socio-scientific issues (hereafter SSI) are complex social problems with technological or conceptual ties to science, including a wide array of timely (and sometimes
Kathryn E. Perez, Monitoring Editor Submitted Jul 2, 2018; Revised Apr 8, 2019; Accepted Apr 11, 2019

CBE Life Sci Educ September 1, 2019 18:ar30 DOI:10.1187/cbe.18-07-0110

Conflict of interest statement: K.M.H. and L.J.K. were involved with the development of the issues-based laboratory curriculum implemented in this study. However, no promotion of a particular product to the exclusion of other similar products should be construed. *Address correspondence to: Lori J. Kayes (lori.kayes@oregonstate.edu).

(C) 2019 K. M. Hewitt et al. CBE-Life Sciences Education (C) 2019 The American Society for Cell Biology. This article is distributed by The American Society for Cell Biology under license from the author(s). It is available to the public under an Attribution-Noncommercial-Share Alike 3.0 Unported Creative Commons License (http://creativecommons.org/licenses/ by-nc-sa/3.0)

"ASCB®" and "The American Society for Cell Biology ${ }^{\circledR}$ " are registered trademarks of The American Society for Cell Biology. 
controversial) topics, such as potential impacts of global climate change and management of invasive species (Sadler, 2009, 2011). Many SSI are rooted in scientific advances and technologies stemming from the biological sciences. These SSI require a certain level of public understanding and consideration of political, economic, and ethical factors. This focus on nonscience aspects of SSI may be undervalued or lacking in formal science curricula and instruction.

The SSI approach is rooted in the science, technology, and society science education movement of the 1970s and 1980s. During this movement, interactions of science or technology and social issues were the focus of either privileged, isolated courses or specific curricular modules in more traditional courses and textbooks. In comparison, a more modern SSI approach integrates many SSI throughout a science curriculum (e.g., a course); uses authentic activities to gather data around or related to the SSI; and requires critical analysis, argumentation, and communication by students regarding the associated science or technology issues and societal concerns (Sadler, 2004).

The SSI approach has been shown to have positive influences on student learning of content (Blumenfeld, 1992; Edelson and Joseph, 2004) and development of student interest in science (Sadler, 2011). A focus on socially relevant issues can help students relate scientific content to their everyday lives and, specifically, increase their motivation to learn science (Deci, 1992; Jarvela, 2001; Sadler, 2009). There are several studies that show that SSI interventions have provided meaningful contexts for learning from a student perspective (e.g., Barber, 2001; Dori et al., 2003; Sadler, 2004, 2009; Bennett et al., 2005; Harris and Ratcliffe, 2005; Bulte et al., 2006; Parchmann et al., 2006; Yager et al., 2006; Lee and Erdogan, 2007; Albe, 2008; Zeidler et al., 2009).

According to Sadler (2004), an SSI approach can strengthen students' efficacy and agency regarding socio-scientific problems, particularly when engaging in moral reasoning and argumentation. These previous findings have led us to question how using this teaching and learning approach might increase students' motivation to engage with the SSI problems and develop potential solutions. The potential impacts of SSI on student motivation are relatively unexplored in undergraduate education with a few notable exceptions (Barber, 2001; Sadler, 2011; Darner, 2012). These studies found that SSI curricula maintained higher student motivation and interest in chemistry (Barber, 2001) and nonmajors science classes (Darner, 2012). Of these, only Darner (2012) addressed university-level students, finding a decrease in amotivation (i.e., not acting at all or acting without intent) when an SSI-type curricula was implemented. On the basis of these findings, we were hopeful that using SSI in the biology laboratory would lead to increases in student motivation to participate in laboratory activities and that our research would contribute to the limited studies in this area.

\section{Motivational Theory and the Impact of Student Motivation on Performance and Persistence}

Motivation theory can be quite complex; here, we attempt to elucidate only the relevant components informing our research. Motivation can be described as either "trait-like" (i.e., a students' less modifiable and seemingly more "natural" disposition toward learning) or "state-like" (i.e., "refer[ing] to students' desires to participate, study and learn in a specific context," Brooks and Young, 2011, p. 49). To understand how SSI might impact student learning in the classroom, we will focus on state-like, or situational motivation, which can fluctuate over short and long periods of time, such as over the course of a term. The state-like nature of situational motivation enables one to assess the motivation of an individual at various time points and in different settings to gauge the influence of curricular treatments over different time points during a course. Additionally, because situational motivation is time limited, it is related more specifically to an individual's motivation to complete a task or participate in an activity (Guay et al., 2000). These attributes of situational motivation provided us with useful measures that would be sensitive to the contexts and time periods that varied in our study.

This study is grounded in the self-determination theory (SDT) of motivation. SDT posits that people who have agency or power over their own choices (i.e., who are self-determined) are the most intrinsically motivated (i.e., engaged in an action for their own sake, pleasure, or enjoyment) with respect to engaging in tasks (Ryan and Deci, 2000; Brooks and Young, 2011). According to SDT, feelings of self-determination are based upon the degree of satisfaction of three basic psychological needs: autonomy, competence, and relatedness (Ryan and Deci, 2000). "Autonomy" concerns the perceived regulatory mechanism for one's own behavior, either the self or other external influences. "Competence" refers to feeling effective in one's ability with respect to certain goals or tasks. "Relatedness" refers to feelings of connectedness or a sense of belongingness with others. In educational contexts, the degree to which students feel self-determined is equatable to their situational motivation to engage in a task, such as taking a science class or studying (Ryan and Deci, 2000).

Motivation has been commonly described as a dichotomy: either 1) intrinsic or 2) extrinsic (i.e., when a person engages in an activity only because he or she desires an outcome afforded by others, such as a reward, avoidance of punishment, or a desire to "look good" to peers). Studies have shown that students' intrinsic motivation regarding education tasks is a strong predictor of their persistence and success (Deci and Ryan, 1985; Renninger, 1992). SDT diverges from the intrinsic/extrinsic motivation dichotomy and, rather, promotes motivation as a continuum of motivational states, including amotivation. Furthermore, SDT breaks down extrinsic motivation into four different categories that represent the continuum between autonomous (driven by internal sources) and controlled regulation (driven by external rewards or punishments; Deci and Ryan, 1985; Ryan and Deci, 2000; see Figure 1). For our research, two of these categories are most included in our chosen survey instrument: 1) external regulation: students' behaviors as inspired by a reward or to avoid negative consequences; and 2) identified regulation: behaviors as more internally driven but still enacted toward a goal required by entities external to the student (i.e., the instructors). The other two categories-introjected regulation (i.e., choosing to do something to not feel guilty) and integrated regulation (i.e., when behavior is motivated by coherence with other aspects of self)are not addressed in this study, as they were not included in the chosen survey instrument (see Methods) in order to minimize survey length (Guay et al., 2000). 
Increased feelings of self-determination

\begin{tabular}{|l|c|c|c|c|c|c|}
\hline $\begin{array}{l}\text { Type of } \\
\text { Motivation }\end{array}$ & Amotivation & \multicolumn{4}{|c|}{ Extrinsic } & Intrinsic \\
\hline $\begin{array}{l}\text { Type of } \\
\text { Regulation }\end{array}$ & External & Introjected & Identified & Integrated & Intrinsic \\
\hline $\begin{array}{l}\text { Level of } \\
\text { Autonomy or } \\
\begin{array}{l}\text { Self- } \\
\text { Determination }\end{array}\end{array}$ & $\begin{array}{c}\text { Lack of } \\
\text { Intentionality }\end{array}$ & \multicolumn{2}{|c|}{ Controlled } & & \multicolumn{3}{|c|}{ Autonomous } \\
\hline $\begin{array}{l}\text { Internalization } \\
\text { of Control }\end{array}$ & $\begin{array}{c}\text { No felt } \\
\text { personal } \\
\text { causation }\end{array}$ & \multicolumn{2}{|c|}{ Low } & \multicolumn{2}{|c|}{ High } & Integrated \\
\hline
\end{tabular}

FIGURE 1. The self-determination continuum showing continuum and relationship between types of motivation, regulation, levels of self-determination, and internalization of control. In the SDT of motivation, extrinsic motivation is divided into four different types of regulation based on the level of internal control. An individual's felt level of autonomy increases as he or she moves from controlled (completely external regulation) to more autonomous (more intrinsic regulation) levels of autonomy or self-determination. Adapted from Ryan, and Deci, 2000; Darner, 2012.

Moving across the self-determination continuum, the perceived control that a person has over his or her ability to participate in activities shifts from more external (controlled) to more internal (autonomous) regulation. The more internal the feelings of control are with respect to a task, the more self-determined or autonomous a student is with respect to that task. Autonomous motivation has been shown to be a predictor of persistence toward postsecondary degree completion (Vallerand, 1997) and increased retention and depth of learning (Grolnick and Ryan, 1989; Vansteenkiste et al., 2006). Additionally, autonomous motivation is positively associated with academic achievement

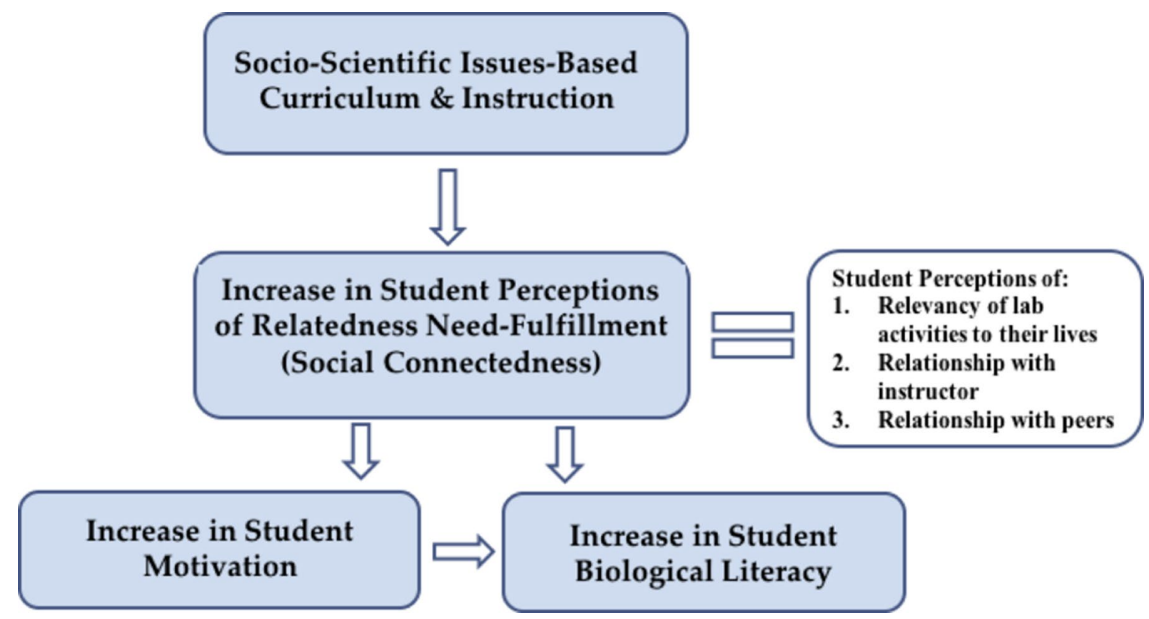

FIGURE 2. Conceptual framework of our study, how SSI curricula might increase motivation and biology literacy. The SSI curriculum is hypothesized to increase the student perception of relatedness with the laboratory activities and, thus, result in an increase in motivation to participate in the laboratory activities. Relatedness is also impacted by relationships between peers and instructors, so these constructs were included in the study.
(Vallerand et al., 1997; Ratelle et al., 2007). In contrast, external regulation and controlled motivation, reflective of low feelings of self-determination, have been associated with negative educational outcomes for students, such as low creativity (Amabile, 1993), anxiety regarding tasks (Ryan and Connell, 1989), lower interest or effort, and lack of personal responsibility for negative outcomes (Ryan and Deci, 2000).

One way in which SSI curriculum may increase motivation is specifically through perceptions of relatedness. There are three major aspects of relatedness that contribute to overall autonomous motivation in classroom contexts, including student perceptions of 1) their relationship with the instructor, 2) their peer relationships, and 3 ) the relevance or importance of the activities to their lives (Darner, 2012). Students' perception of curricular relevance to their lives outside the classroom may increase students' perceptions of social connectedness (i.e., relatedness; Darner, 2007, 2009). Darner (2009, 2014) found that, after participation in an SSI curriculum in a nonmajors biology course, students reported feeling more connected to their communities and were able to relate what they learned to their daily lives. On the basis of these outcomes, the author posited that these students had increased feelings of relatedness. From our perspective, relatedness is of particular interest due to the potential relationship between students' perceptions of the curriculum and their feelings of relatedness (see Figure 2 for conceptual framework). Fostering relevance for students may increase perceptions of both autonomy and relatedness. The current study assesses not only how the SSI model impacts overall motivation, but also specifically the impact of SSI on feelings of relatedness.

This study adds to the existing knowledge base in a number of ways: 1) by using a rigorous quasi-experimental design with both treatment and control groups analyzed with hierarchical linear modeling techniques; 2 ) by adding to the limited research studies regarding the SSI approach in postsecondary settings; 3 ) by exploring a more nuanced notion of motivation with regard to feelings of relatedness; and 4) by investigating of how student motivation changes over the term of a course.

\section{The Current Study}

Before determining how SSI might impact student motivation, we sought to determine whether SSI impacted student motivation, particularly motivation to participate in lab activities, compared with a control group. We conducted a quasiexperimental study in three introductory 
biology courses in which approximately half the laboratory sections were taught using the newly developed curriculum based on the SSI model (SSI treatment) and the other half of the laboratory sections were taught using the traditional curriculum already in place (control curriculum). Specifically, we examined 1) whether and how the motivation in both groups (SSI and control) changed over the course of the term, 2) whether or not the SSI-based curriculum had the potential to cause a shift in student motivation toward the more internally regulated (i.e., autonomous control) side of the SDT continuum for students in the SSI treatment group compared with the control group, and 3) the effect of the SSI-based curriculum specifically on students' feelings of relatedness to the curriculum, their peers, and their instructors.

We hypothesized that the SSI laboratory curriculum would shift students' along the continuum toward more internally regulated (autonomous) motivations relative to the control group that received the traditional curriculum over time. More specifically, because of the focus of the SSI curriculum on fostering relevance for students through the contextualization of content with locally and globally relevant SSI, we hypothesized that SSI would shift student motivation to engage in laboratory work toward more autonomous types of motivation by enhancing feelings of relatedness (Figure 2).

\section{Research Questions}

1. What types of motivations are salient for undergraduate students in an undergraduate introductory biology course?

a. How do the levels of the different types of motivation change over the course of the term?

2. What was the effect of an SSI-based laboratory curriculum on undergraduate biology students' levels of autonomous and controlled motivations with respect to engaging in laboratory work compared with the control group?

a. How did these levels of autonomous and controlled motivations change over the course of the term?

2. What was the effect of an SSI-based laboratory curriculum on undergraduate biology students' perception of relatedness?

a. What were the differences between the SSI and control groups in student perceptions of the relevance of the learning activities?

b. What were the differences between the SSI and control groups in student perceptions of their relationships with their instructors?

c. What were the differences between the SSI and control groups in student perceptions of their relationships with their peers?

\section{METHODS}

\section{Educational Context}

SSI and Control Curricula. Students in the SSI sections were taught concepts (genetics, evolution, and ecology) similar to those presented in the previously existing traditional curriculum, but via new modules that integrated the SSI approach, based on recent biology education research, practitioner publications, or new activities developed "in-house" (see the Supplemental Material). The SSI curriculum was designed to address both global and local topical issues assumed to be relevant to most students and to help develop biology literacy, such as genetic testing, genetic modification of crops, and local invasive species. The SSI curriculum (a compilation of laboratory modules) conformed to the guidelines for SSI-based instruction based on the model by Lenz and Willcox (2012). Each SSI laboratory module aligned with biological concepts deemed important to the course within a larger sequence of three courses. In the SSI model, the curriculum must initially motivate students by providing a socio-scientific issue or problem to help contextualize their learning. To meet this goal in the SSI curriculum, students were required to individually watch and/ or read and answer questions about various videos and news and scientific articles addressing a specific socio-scientific issue before coming to lab. At the beginning of each laboratory period, graduate teaching assistants (GTAs) then led a 20- to 30-minute group discussion related to the socio-scientific issue that engaged students in active learning (think-pair-share, jigsaw, write and pass, minidebate, role plays, etc.). Following the discussion, students completed inquiry-based laboratory activities that allowed them to develop hypotheses and interpret results with a set of prescribed methodologies or that encouraged them to develop the hypotheses and methodology and interpret results for predefined research questions (Hofstein and Lunetta, 2004). At the end of each laboratory period, students reflected back on the socio-scientific issue and were asked to determine whether their opinions or viewpoints had changed or whether they were inspired to consider a new approach to addressing the socio-scientific issue. Hewitt et al. (2014) present one module of the SSI curriculum that uses the socioscientific issue of invasive species management to contextualize animal behavior concepts.

The control laboratory curriculum consisted of modified activities from a widely used laboratory manual concerning the same biological content as the SSI curriculum. In the control curriculum, activities were not contextualized to provide realworld relevance or relate to SSI. Students completed pre-labs with questions related primarily to biological content and concepts, and, at the beginning of the lab, GTAs gave a short lecture to introduce the lab activities. Following this introductory lecture, students engaged in the prescribed lab activities with outcomes that students could easily anticipate (i.e., "cookbook labs"). For example, the animal behavior pre-lab would introduce some relevant concepts and ask a series of questions to ensure students read the laboratory introduction. The in-lab activities consisted of observing behaviors with different organisms and answering questions in the laboratory manual to ensure activities were completed. Some questions would relate to predicting behaviors in different contexts, but students were not required to consider an issue or engage in activities designed for problem-solving of real-world issues.

Course Structure and Curricular Implementation. We implemented the SSI curriculum and the control curriculum simultaneously in 25 laboratory sections of three introductory biology for life science majors courses during a 10-week Spring term at a large research university in the Pacific Northwest (Figure 3). The lectures associated with these laboratory sections did not utilize an SSI framework in curriculum or instruction. Because the SSI curriculum was implemented in the laboratory sections only, students were randomized at the laboratory section level. 


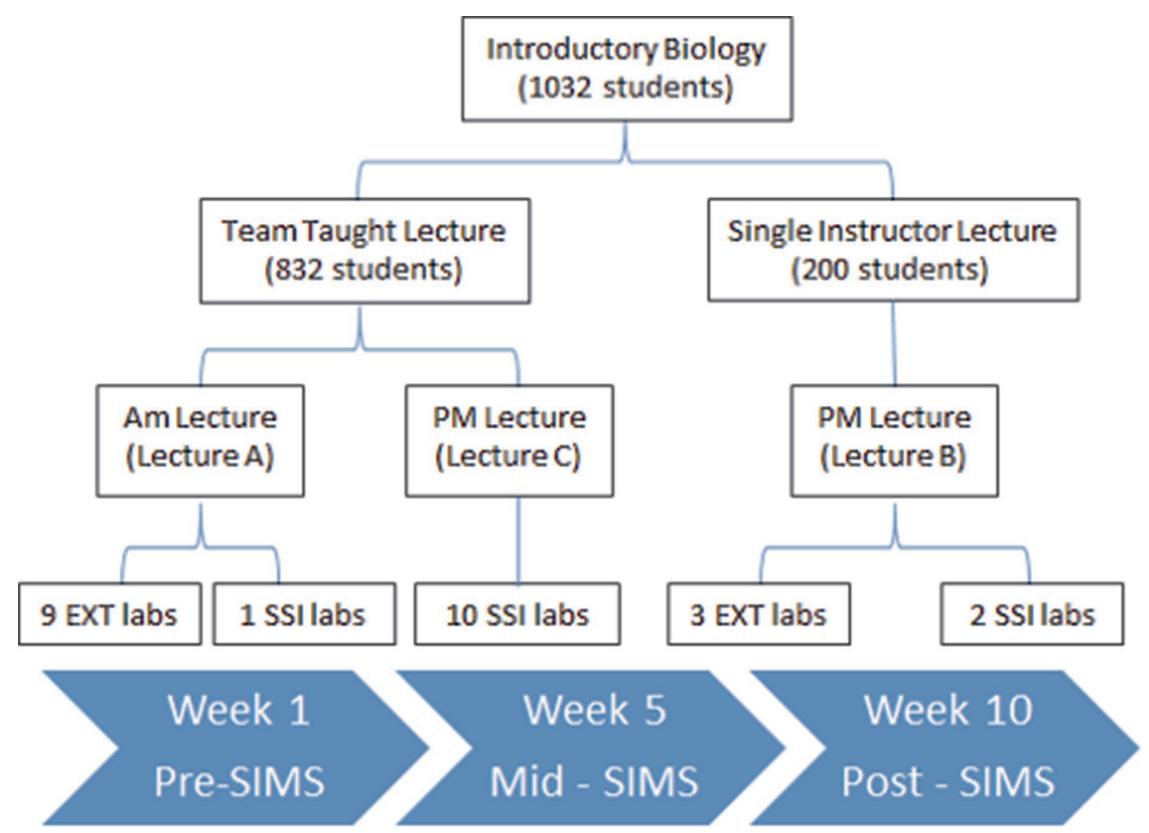

FIGURE 3. Hierarchical course structure of introductory biology for science majors and laboratory curricular implementation. The study was implemented in the laboratory sections of a lecture/lab combined course with three different lectures and 25 lab sections. The SSI and control curricula were divided approximately evenly within each lecturer or lecturer team. The SIMS was offered to all students three times (at the beginning of the term, in the middle of the term, and at the end of term). AM, class taught in the morning; EXT, control group; PM, class taught in the afternoon.

term; and 3) postterm: during the final week (week 10) of the term after their last lab session. The postterm survey also included three open-response questions related to student perceptions of relatedness and general demographic questions. Six hundred and ninety-eight students took part in all three surveys and thus are reported in the Results $(n=698)$.

\section{Situational Motivation Scale}

The SIMS (Guay et al., 2000) is composed of 16 Likert-scale items, with four questions per each motivational subconstruct assessed, that is, intrinsic motivation (IM), amotivation (AM), and two types of extrinsic motivation, identified regulation (IR) and external regulation (ER). As stated previously, the SIMS does not measure either the integrated regulation or the introjected regulation types of extrinsic motivation, due to a desire to streamline the survey and ensure students responded accurately without survey fatigue (Guay et al., 2000). The SIMS was determined to be the most adequate survey for our research questions per its design to measure situational motivation within a certain context (e.g., in a biological laboratory course). Additionally, there have been extensive studies on the validity and

The majority of the students $(n=832)$ were enrolled in two team-taught lectures (lectures A and C in Figure 3), which were taught identically by the two instructors, with one instructor teaching the first 5 weeks and the other instructor (L.K.) teaching the second 5 weeks of the 10-week term. A smaller lecture section $(n=200)$ was taught by a different single instructor for the entire term (lecture B in Figure 3). The laboratory sections were taught by GTAs who were assigned to lab section and curriculum (either SSI or control) based on their availability. Both curricula had a mix of male and female GTAs, with similar average teaching and teaching professional development experiences. GTAs were trained in a similar manner on curricular implementation, regardless of being assigned to teach the SSI or control curriculum.

\section{Sample and Participant Assignment}

The participants in this study were undergraduate students ( $n=$ 1032) enrolled in the introductory life science majors' biology course. Students were told during the first lecture of the course that the biology program was implementing different curricular types and assessing the impacts on the students' experiences for future course curricular decisions. Students were assured that they would get the same content and would be taught via acceptable instructional strategies but were not told which curriculum (SSI or control) they would receive in lab.

Students were asked to complete an online version of the Situational Motivation Scale (hereafter SIMS; Guay et al., 2000) three times: 1) preterm: before their first lab session during the first week of the term; 2) midterm: in week 5 of the reliability of the SIMS and the relationship of the scale items to SDT (Guay et al., 2000; Standage and Treasure, 2002).

The SIMS was slightly modified to be specific to the context of a biology laboratory course. To this end, minor changes were made to the SIMS response statements to say "for the biology XXX lab" instead of "this activity." Students responded on a scale of 1 to 7 , where 1 corresponds to "not at all" and 7 corresponds exactly to a series of statements. The statements were rated in response to the stem, "Why are you doing the work for the biology XXX lab?" Cronbach's alpha was calculated for the subscales from preterm participant survey scores to ensure reliability of the measure in this study (IM $=0.91, \mathrm{IR}=0.87, \mathrm{ER}=$ 0.83 , and $A M=0.91)$. Analyses included scoring for each one of the four subconstructs for students at each time point.

In addition, as previously described by researchers (Vallerand, 1997; Levesque et al., 2004), we calculated a self-determination index (SDI) using all four subconstruct scores. The SDI has been shown to be a valid metric for self-determination (Vallerand, 1997). It is calculated by weighting the subconstructs of the self-determination continuum, with heavier positive weight for intrinsic motivation (IM) and negative weight for amotivation (AM) to reflect the extreme ends of the motivational continuum described in SDT (see Figure 1 again for reference). Calculating SDI enables the analysis of a single score on the SIMS, which was important for the hierarchical quantitative analyses discussed in Data Analysis. SDI was thus calculated as

$\mathrm{SDI}=2 \times \mathrm{IM}+\mathrm{IR}-\mathrm{ER}-2 \times \mathrm{AM}$ 
SDI scores can range from -18 to +18 , with the more negative values representing lower feelings of self-determination (i.e., controlled motivations).

\section{Open-Response Survey Questions}

To qualitatively assess the impact of relatedness need fulfillment on situational motivation, we included three openresponse questions in the survey. The questions were designed to allow deeper investigations into why the SSI curriculum might promote a shift on the SDT motivation continuum. The questions were as follows:

1. Please describe your relationship with the lead graduate teaching assistant for your biology lab class. For example, did they address your questions/concerns? Did they seem excited to teach you biology?

2. Please describe your relationship with your peers in your biology lab class. For example, did you get along? Was the work distributed fairly?

3. Explain how the activities in your biology lab relate to your personal life or future career goals, if at all.

\section{Data Analysis}

Hierarchical Analyses. While all data were analyzed on the student level, the curricular treatments were implemented at the lab-section level. Thus, there is a clear hierarchical nature in the experimental design; students were nested in labs, which were nested in lecture sections, which were nested in lecturer(s), creating a clustering of groups (Figure 3). Current literature has argued for the need to account for the nested experimental design structures in statistical analyses. Hierarchical linear modeling (HLM) is becoming more prevalent in education research studies for this reason (Raudenbush, 1997; Matsumura et al., 2013). The clustering of groups was accounted for in all quantitative analyses, using HLM (Raudenbush, 1997) to allow for unbiased estimates of the treatment effect. HLM analysis accounts for within- and between-group variances, which increases the accuracy of treatment effect estimates compared with comparing subgroup means (Raudenbush and Bryk, 2002; Liu et al., 2008). HLM allows for testing curricular effects with covariates such as lecture section, lab section, and so on, as well as exploration into how the effect of curriculum varies temporally across the term. The resulting HLM analyses of the SIMS scores and SDI index allowed us to account for confounding factors in the experimental design. For example, different GTAs might differ in instructional style, ability, and adherence to the curricular model, resulting in slightly different implementations of the curriculum (Gardner and Jones, 2011). These difference could lead to individual students within a single laboratory section having more similar motivation scores to one another than to other students in different lab sections.

Owing to the unbalanced distribution of curricular implementation within different lecture courses, differences in SDI index and subgroup scores were tested across the different lecture times/sections. Owing to lack of significance, lecture time/ section was deemed a random effect in the model, allowing us to account for variance between lecture sections and for differences in lecturers. Additionally, we accounted for the temporal correlation between time-point observations from the same students who took part in all three surveys (preterm, midterm, and postterm) through repeated-measures methods.

To assess the effect of the SSI lab curriculum on student self-determination scores, we tested the fixed effects of the curriculum treatment and the time by curriculum treatment interaction. The latter fixed effect examines how the effect of the curricular treatment on students' motivation changed throughout the term. Data were analyzed using SAS PROC MIXED (SAS Institute, 2008). We used a Satterthwaite approximation to account for the lack of balance in the responses for degrees of freedom, as the laboratory sections were not equally distributed across lecture sections and times.

The following is the complete saturated statistical model:

$$
\begin{aligned}
Y_{i j k l m n o p}=\mu & +\alpha_{i}(\text { curriculum })+\beta_{j}(\text { time })+(\alpha \beta)_{i j}+\gamma_{k}+\delta_{l(k)} \\
& +\zeta_{m(k l)}+\eta_{n(k l m)}+\theta_{o}+\imath_{p}+\varepsilon_{i j k l m n o p}
\end{aligned}
$$

- $Y_{\text {ijklmnop }}=$ measure of motivation (subconstruct or SDI) of the $n$th student nested in the $m$ th lab nested in the lth section nested in the $k$ th lecture at the $j$ th time receiving $i$ th curricular treatment

- $\mu=$ the overall mean

- $\alpha_{i}=$ fixed effect for the $i$ th curricular treatment

○ $i=1,2$, where control curriculum is 1 and SSI curriculum is 2

- $\beta_{j}=$ fixed effect of the $j$ th time measurement

○ $j=1,2,3$

- $(\alpha \beta)_{i j}=$ fixed interaction of the ith curriculum treatment and the $j$ th time

- $\gamma_{k}=$ random effect of $k$ th lecture

$\circ \gamma_{k} \sim N\left(0, \sigma_{\gamma}^{2}\right)$

- $\delta_{l(k)}=$ random effect of the $l$ th section nested in the $k$ th lecture

○ $\delta_{l(k)} \sim N\left(0, \sigma_{\delta}^{2}\right)$

- $\zeta_{m(k l)}=$ random effect of the $m$ th lab nested in the $l$ th section nested in the $k$ th lecture

○ $\zeta_{m(k l)} \sim N\left(0, \sigma_{\zeta}^{2}\right)$

- $\eta_{n(k l m)}=$ random effect of the $n$th student nested in the $l$ th lab nested in the $m$ th section nested in the $k$ th lecture

- $\eta_{n(k l m)} \sim N\left(0, \sigma_{\eta}^{2}\right)$

Analysis of Open-Response Data. The students' answers to the open-response questions were analyzed within QSR International's NVivo10 software (v. 10; QSR International, 2012). Analysis was primarily theory driven, with SDT in mind (Krippendorff, 1980; Weber, 1990; Namey et al., 2007). Analysts also used thematic analysis of students' responses when appropriate (Auerbach and Silverstein, 2003), allowing for some emergent themes grounded in the data (Glaser and Strauss, 1967; Namey et al., 2007).

Coding of all data was done by one researcher using a blinded coding process. Before being coded, data were de-identified (K.H.) in terms of the relevant curriculum (SSI or control) associated with students' responses in an attempt to prevent coding bias. Codes were later segregated by corresponding curriculum once all coding was complete. Another researcher coded 5\% of the data, and interrater scoring demonstrated good interrater agreement (73\%). As an additional measure, the coding 
processes and emerging codes were discussed with multiple external researchers (Patton, 2002, pp. 465-466).

Although these were qualitative data from open-response questionnaires, we chose a quantitative analysis due to the large number of small units of texts (1-3 sentences long). Converting qualitative data into quantitative data for analysis is a common practice, especially when data from many participants are collected (Bernard, 1996). Upon completion of the coding, NVivo was used to generate code frequency reports. These reports uncovered coding themes in the data for each question on the questionnaires, separated by curriculum (SSI and Control). Specifically, frequencies were determined "on the basis of the number of individual participants who mention[ed] a particular theme" (Namey et al., 2007, p. 143). Nonparametric two-sample proportion tests were used to compare the frequencies of each code for each question between the two curricula. Differences were deemed significant at $p<0.05$. To highlight the most prevalent themes, we omitted any code that represented less than $5 \%$ of the total responses to a particular question for both curricula combined.

\section{RESULTS}

\section{Student Demographics}

There were similar numbers of student responders in each curriculum (SSI curriculum: $n=443$; control curriculum: $n=418$ ) with similar demographics. The majority of the students reported being between ages 18 and 22 years. The majority of students were female (SSI: 58\%; control: 59\%) and European or white (SSI: 67\%; control: $72 \%$ ) in both groups. The next most frequently reported ethnicity was Asian or Asian American (SSI:17.2\%; control:13.9\%), while all other race/ethnic origin categories represented less than $10 \%$ of the total enrollment in both curricula.

\section{Response Rates}

The HLM analysis included only those who participated in all three surveys ( $n=698$ ) in order to assess individuals' motivation over time. The response rate for completing all three surveys was $72 \%$ with no statistically significant differences regarding completion between SSI and control groups. Individual lab section response rates varied from 56 to $86 \%$, with similar low and high rates in both SSI and control groups. Of the 968 students enrolled in the classes at the end of the term, 861 participated in the postterm survey, with an overall response rate of $89 \%$ for the three questions on relatedness.

\section{Curricular Effects Using the Self-Determination Index}

Students in the SSI curriculum had an increased score on the SDI motivational index that was, on average, 1.394 higher $(F=$ 12.16; $\mathrm{SE}=0.40 ; d f=28 ; t=3.49 ; p<0.005)$ than those in the control curriculum (see Figure 4). This higher score in the SSI curriculum indicates a shift toward more autonomous forms of motivation.

The difference in SDI scores between the SSI and control groups was determined from an average of the lab section scores. Many of the lab sections in the SSI groups had significantly higher SDI scores than the control groups. While there was no difference in SDI scores between SSI and control groups in the preterm surveys, students in the SSI group had significantly higher SDI scores than the control group in both the

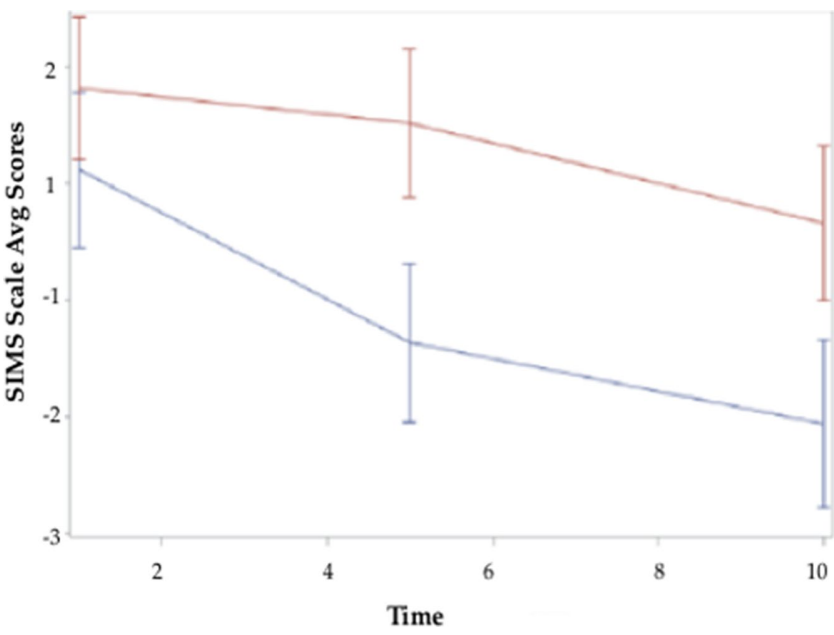

FIGURE 4. Difference in average and $95 \%$ confidence intervals $(F=12.16 ; p<0.005)$ in student SDI scores (SIMS average scores) and $95 \%$ confidence intervals between the control (blue) and SSI (red) curricular treatments for all laboratory sections in the control and SSI groups over time (preterm $=0$, midterm $=5$, postterm $=10$ ). SDI scores can range from -18 to +18 .

midterm and postterm surveys (Figure 4). There was a significant effect of time on SDI score over the course of the term $(F=$ 13.42; $p<0.001$ ), in that students' motivation in both treatment groups decreased over the course of the term. There was not a significant curriculum by time interaction $(F=2.24$; $p<$ 0.1073).

\section{Curricular Effects Broken out into Subconstructs}

We also investigated the differences between the SSI and control groups in the four subconstructs of motivation represented on the SIMS survey individually to get a better sense of the types of motivations that were most salient over the course of the term.

Autonomous Regulation. For intrinsic motivation, there was strong evidence of an effect of curricular treatment $(F=27.85$; $p<0.0001$ ) and an interaction between curricular treatment and time $(F=2.20 ; p<0.01)$. These results indicate that, at the end of the term, intrinsic motivation was significantly higher in the SSI group than in the control group. Compared with the preterm survey, intrinsic motivation was lower in both the control and the SSI groups at both the midterm and the postterm surveys. However, the decrease is significantly less for the SSI group than for the control group. For identified regulation, there is similarly strong evidence of an effect of curricular treatment $(F=11.13$; $p<0.005$ ) but no interaction between curriculum and time $(F=2.20 ; p>0.1)$. It appears that identified regulation decreased for both treatment groups throughout the term; however, there was a larger decrease in the control group between preterm and midterm in comparison with the SSI group. At the end of the term, students in the SSI group had higher internal regulation than those in the control group.

Controlled Regulation. There is strong evidence that there is an effect of curricular treatment on external regulation ( $F=$ 45.86; $p<0.05)$ but no evidence of an interaction between 


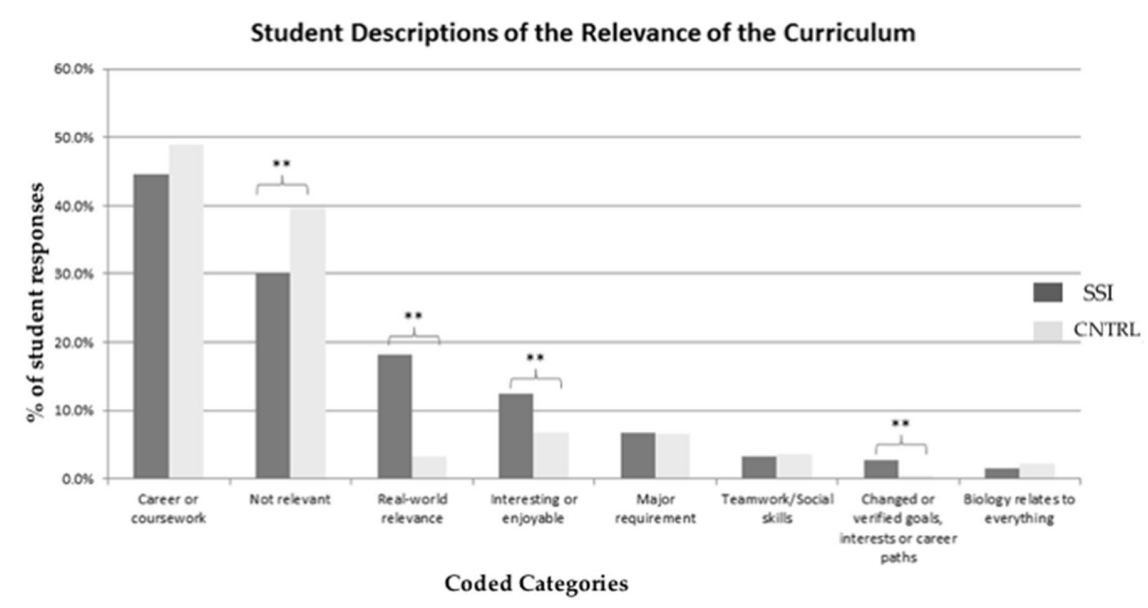

FIGURE 5. Student descriptions of the relevance of the curriculum. Coded student responses to the questionnaire question asking students to explain the relevance of the lab activities to their daily lives and/or future career goals for the SSI $(n=435)$ and control ( $n=415)$ groups. Categories with significant differences between the two curricula determined by the two-sample proportion tests are indicated with asterisks $\left(^{*}, p<0.05\right.$; $\left.{ }^{* *}, p<0.01\right)$.

curricular treatment and time $(F=0.82 ; p>0.4)$. It appears that external regulation changes very little throughout the term for the control group. On the other hand, as time goes by, the external regulation for the SSI group decreases. The SSI group had lower external regulation than the control group at the end of the term.

Amotivation. In general, over time, amotivation increases for both groups. However, the increase is greater for the control group compared with the SSI group. There is strong evidence of an effect of curricular treatment for amotivation $(F=4.28$; $p<$ $0.06)$. However, there is no evidence of an interaction between curricular treatment and time on amotivation $(F=0.53$; $p>0.5)$. The SSI group had lower amotivation scores than the control group at the end of the term.

Postterm Open-Response Question Coding Results. In the SSI curriculum, fewer students indicated that the lab activities were not relevant to their daily lives or future careers compared with students in the control curriculum (Figure 5; SSI = $30.1 \%$; control $=39.8 \%$; $p<0.005$ ). Additionally, more students indicated realworld relevance $(\mathrm{SSI}=18.2 \%$; control $=$ $3.2 \% ; p<0.001$ ) or interest (SSI $=12.4 \%$; control $=6.7 \% ; p<0.01$ ) regarding the laboratory activities in the SSI curriculum than in the control curriculum. Another theme that differed between SSI and control curricular groups was a change or affirmation of career goals (SSI $=2.8 \%$; control $=0.5 \% ; p<0.01$ ).

A significantly higher percentage of SSI students than control students described their GTA as excited to teach (SSI $=41 \%$ of responses; control $=33 ; p<0.05$; Figure 6 ). There was also significantly higher percentage of positive responses concerning GTA quality from students experiencing the SSI curriculum versus the control curriculum (SSI $=57.2 \%$; control $37.3 \% ; p<0.01)$. Significantly fewer students $(p<0.01)$ in the SSI group (3.2\%) described their relationship with their GTA negatively or as nonexistent compared with the control group (7.5\%).

The final open-response questions explored themes related to student-student relationships in the context of the laboratory class. There were no significant differences in coded categories related to student-student relationships between student groups receiving the two different curricula (Figure $7 ; p>0.05$ ).

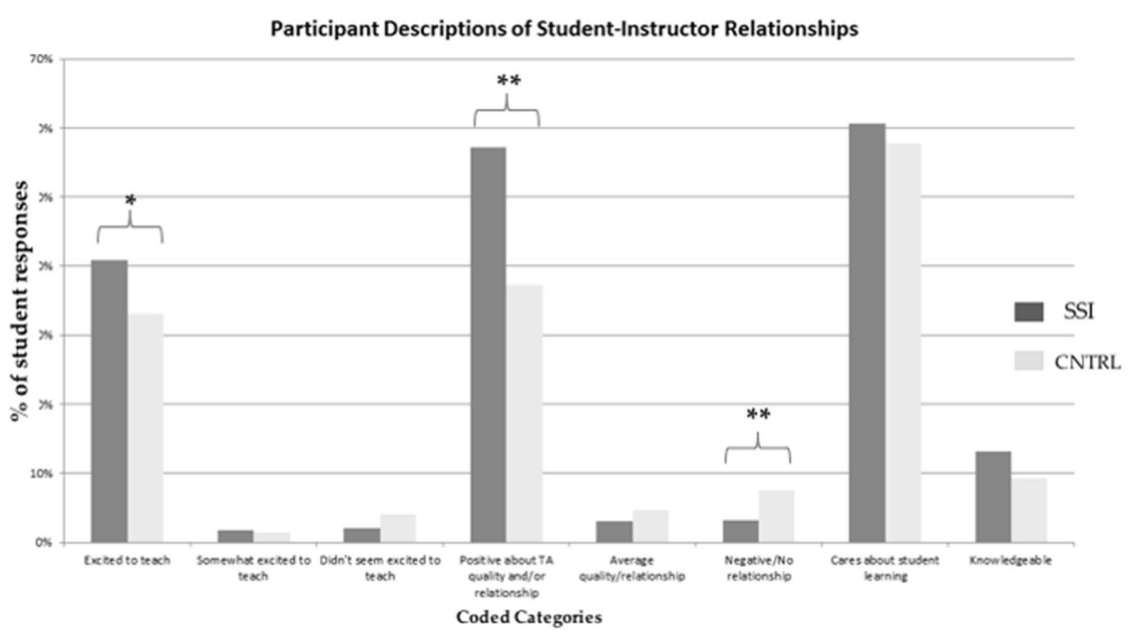

FIGURE 6. Participant descriptions of student-instructor relationships. Coded student responses to the question asking students to describe their relationships with their GTAs for the SSI $(n=435)$ and control $(n=415)$ groups. Categories with significant differences between the two curricula determined by the two-sample proportion tests are indicated with asterisks $(*, p<0.05 ; * * p,<0.01)$.

\section{DISCUSSION}

Proponents of the SSI approach to science education have found that the use of socially relevant issues helps students relate scientific content to their everyday lives and may increase their motivation to learn science (Sadler, 2009). Several studies show that SSI interventions provide motivating contexts for learning from a student perspective (Barber, 2001; Sadler, 2004, 2009). Additionally, of more than 200 empirical education studies in which the SDT framework has been applied to investigate educational outcomes or motivational profiles of students, few have focused on undergraduate introductory courses or the effects of curricular innovation on student motivation (Guay et al., 2008). To date, our study is one of the first to investigate undergraduate biology majors' motivation with regard to an SSIbased curriculum, and, specifically, in 


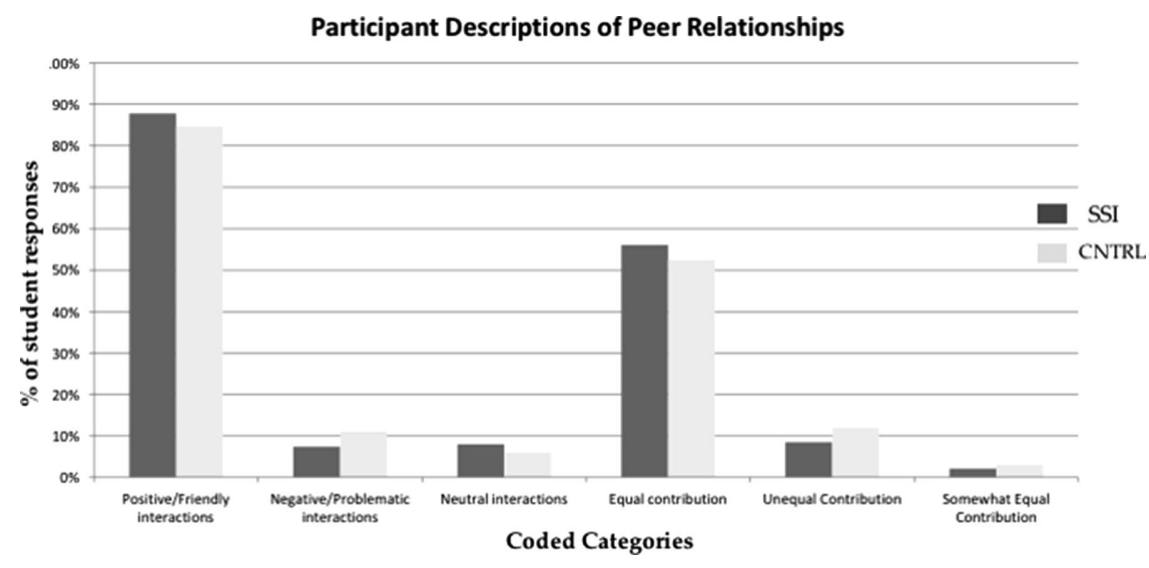

FIGURE 7. Participant descriptions of peer relationships. Coded student responses to the question asking students to describe their relationships with their peers for the $\mathrm{SSI}$ ( $n=$ $435)$ and the control $(n=415)$ groups. Categories with significant differences between the two curricula determined by the two-sample proportion tests are indicated with asterisks $(*, p<0.05 ; * *, p<0.01)$.

comparison with a traditional curricular control group. Weighting the scores of the subconstructs to compute a single motivation score (SDI) from the SIMS allowed us to reduce the number of motivational components in the analysis and better visualize the treatment effects in the various lab sections over time (Ratelle et al., 2007). Overall we found the lab section SDI averages were not only significantly higher for the SSI curriculum, but they also had significantly lower variance. The reasons for this lower variance may have been in part due to the effects of the SSI curriculum being structured so that student motivation was less GTA dependent. Indeed, standardizing the experience of students in these various sections nested in the larger lecture courses is an ongoing practical concern, as GTAs often have no formal pedagogical training, and yet they play a large role in science education at institutions of higher education (Gardner and Jones, 2011).

In addition to adding to these knowledge bases, analyzing the data according to the individual subconstructs of motivation from the self-determination continuum allowed us to investigate the effects of the treatments on intrinsic motivation, integrated regulation, external regulation, and amotivation over the course of the term. The analysis of the subconstructs in the SIMS from the self-determination continuum revealed that motivation types deemed more autonomous (intrinsic motivation and identified regulation) declined over the course of the term. This finding aligns with previous research that has indicated that more intrinsic motivations regarding academic activities can decrease as the time for evaluation of those activities approaches (Wicker et al., 2004). We conjecture that, as a final exam approaches near the end of the term, students may feel more external pressure (and regulated motivation) concerning awarding of exam and course grades by their instructors. Indeed, competitive and evaluative environments are correlated with more controlled types of student motivation concerning academic activities (Guay et al., 2008). Thus, students in both the SSI and control curriculum groups may have perceived their lab courses in this evaluative light as the term progressed. Yet, given our findings that students experience less of a decrease in autonomous moti- vation with the SSI curriculum, we suggest a possible buffering effect of the SSI curriculum on the more typical decrease in motivation as students move into the stressful and demanding end portion of the course. This conclusion is consistent with other research showing that classroom contexts that support feelings of self-determination (notably via faculty supporting student autonomy) negate the less autonomy-supportive aspects of academic programs such as competition with peers for a limited number of high grades (Sheldon and Krieger, 2007; Guay et al., 2008).

Our study also explored the effect of the SSI curriculum on undergraduate biology students' perception of relatedness to curricular topics, their instructors, and their peers. We found that student perceptions of relatedness with the curricula and GTAs were different between the two students groups, with students experiencing the SSI curriculum claiming greater relatedness with both. We assume that part of the reason for this finding, and the related findings concerning autonomous motivation differences overall, is that the SSI curriculum focused heavily on locally and globally relevant issues that were potentially more relevant for students, as previously documented (Darner, 2009, 2014). SDT researchers have found that autonomous motivations are more likely to occur when a student's need for relatedness, or social connectedness (in addition to competence and autonomy) is adequately fulfilled (Deci et al., 1991). The need for relatedness has been described as needing to feel a sense of social belonging. In the classroom context, the relevance of the learning and student relationships with peers and instructors are particularly important to fulfilling the relatedness need (Ryan and Deci, 2000). The higher positive perceptions of student-GTA relationships was also not an expected finding. More research is needed to further investigate the nuances in the SSI model's impact on student-instructor interactions. It is possible that the novel inquiry-based methods associated with the SSI curriculum may have been a confounding variable regarding various findings, and especially with respect to perceived GTA enthusiasm and quality. It is also possible that, despite the randomization of GTAs teaching the different curricula, there were one or two more engaging GTAs in the SSI group than in the control group.

There were no differences in student perceptions of peer relationships between the SSI and the control curriculum groups. The overwhelming majority of students in both curricula reported positive, friendly interactions with their peers in lab. Most indicated that the peers in their lab groups contributed equally to completing the lab exercises. It is possible that the unique setting of the laboratory climate and requirement in both curricula of cooperative interactions with peers ultimately were more powerful predictors of student relatedness than the curricular nuances.

\section{Implications, Limitations, and Future Directions}

We believe there is practical utility in using a motivational framework to explore and plan for student success. This study 
may help practitioners identify ways to create learning environments that support students' autonomous motivations in large introductory courses, namely via SSI-based curricula. Moving beyond studies that simply assess intrinsic and extrinsic motivation, our study additionally provides educators insight into the worth of SSI curricula for nuanced aspects of motivation shown to be critical for student success (i.e., perceived relatedness to curriculum and instructors). Our results indicate than these more proximate SSI curriculum-related outcomes help accomplish the more ultimate goal of functional biological literacy or students' ability to understand, problem solve, and communicate with regard to timely and complex real-world biology-based problems. Finally, we hope that our study might serve as a methodological model for others doing discipline-based education research, with the novel nested design allowing researchers to attend to potential confounding factors in quasi-experimental design, such as class sections, instructors, and so on.

However, additional methodological limitations to this study must be acknowledged. Most problematic, and alluded to earlier, is that it is not possible to discern from our data which aspect of the SSI curriculum can be credited with the observed student outcomes. Indeed, a number of curricular and instructional aspects that were part of the SSI treatment are known to be associated with positive student outcomes, including realworld relevance of the curriculum, inquiry-based and problem-solving exercises, and the student reflection exercises at the end of each SSI lab. Also, because students were not surveyed after every lab period, our study design did not allow for the analysis of the impact of individual lab modules on student motivation or relatedness with respect to SSI, GTAs, and peers. Ultimately, in considering our study results, the SSI curricular model that we used must be considered as a whole. At the same time, the coded responses of the open-ended survey questions strongly indicate that the contextualized SSI issues had a potentially isolatable effect on student motivation and perceptions of relatedness. Given the voluminous body of research indicating inquiry-based pedagogy and student reflection are "best practices" in promoting student learning, we are hesitant to suggest that further study should be conducted on the potential of SSI devoid of these other strategies.

Additional study limitations pertain to the results around relatedness. It has been suggested by others that a student's ability to perceive the value in the learning activities depends on the social connections made in relatedness need fulfillment (e.g., Deci, 1992). Yet, as predicted by SDT, it is highly likely that students also felt a greater sense of autonomy when engaged with the SSI curriculum particularly, due to the inclusion of more authentic science activities. More research is needed to ascertain the relationship between relatedness and autonomy and potential overlap between these two needs in impacting student motivation. Regardless, the results of this study support the conceptual framework guiding the hypotheses and research questions (Figure 2) around the connections between autonomous motivations in SDT, the SSI model, and the importance of relevance to increasing motivation. Although we made no direct assessment of the development of functional biological literacy, we have extrapolated that quotes from students regarding their ability to make connections with content and real-world issues and their daily lives indicate a positive outcome and link in the conceptual framework. Future research studies could identify and implement more direct assessments of functional biological literacy along with motivational constructs of SDT related to SSI.

The fact that this curricular implementation took place at a single institution, and thus the subsequent limits to generalizability, must be also acknowledged. Additionally, "treatment diffusion" could have biased this study, given that it took place in the same institution, and students almost certainly shared their experiences in the laboratory curriculum across the control and SSI groups. To control for treatment diffusion effects, a cohort model design could be used in future studies when a new SSI curriculum is implemented in large courses.

Still, given these limitations, we believe that our study, because it is a large quasi-experimental study with the presence of a control group, added to the literature base regarding undergraduate motivation and relatedness in biology and with respect to SSI curricula specifically. We conclude that the use of an SSI curriculum in large introductory biology laboratory courses may yield positive effects on the motivation of students, including buffering a typical decrease in student motivation over the term of a course. This increased motivation and buffering effect could potentially increase students' success and persistence in biology courses and programs and in attending to pressing issues of great societal import.

\section{ACKNOWLEDGMENTS}

We thank the graduate teaching assistants, faculty, and students who participated in piloting the SSI curriculum and filling out the survey instruments. We also thank David Hubert, Ehern Bentz, and two anonymous reviewers who helped greatly in clarifying and strengthening our paper.

\section{REFERENCES}

Albe, V. (2008). When scientific knowledge, daily life experience, epistemological and social considerations intersect: Students' argumentation in group discussion on a socio-scientific issue. Research in Science Education, 38, 67-90.

Amabile, T. M. (1993). Motivational synergy: Toward new conceptualizations of intrinsic and extrinsic motivation in the workplace. Human Resource Management Review, 3, 185-201. doi: 10.1016/1053-4822(93)90012-S

American Association for the Advancement of Science (AAAS). (1989). Science for all Americans. New York: Oxford University Press.

AAAS (2011). Vision and change in undergraduate biology education: A call to action. Washington, DC.

Auerbach, C. F., \& Silverstein, L. B. (2003). Qualitative data: An introduction to coding and analysis. New York: NYU Press.

Barab, S. A., \& Plucker, J. A. (2002). Smart people or smart contexts? Cognition, ability, and talent development in an age of situated approaches to knowing and learning. Educational Psychologist, 37, 165-182.

Barber, M. (2001). A comparison of NEAB and Salter's A-level chemistry: Students views and achievements. York, UK: University of York.

Bennett, J., Grasel, C., Parchmann, I., \& Waddington, D. (2005). Context-based and conventional approaches to teaching chemistry: Comparing teachers' views. International Journal of Science Education, 27, 1521-1547.

Bernard, H. R. (1996). Qualitative data, quantitative analysis. CAM Journal, 8 , 9-11.

Blumenfeld, P. C. (1992). Classroom learning and motivation: Clarifying and expanding goal theory. Journal of Educational Psychology, 84, 272-281.

Brooks, C., \& Young, S. (2011). Are choice-making opportunities needed in the classroom? Using self-determination theory to consider student motivation and learner empowerment. International Journal of Teaching and Learning in Higher Education, 23, 48-59. 
Bulte, A., Westbroek, H., de Jong, O., \& Pilot, A. (2006). A research approach to designing chemistry education using authentic practices as contexts. International Journal of Science Education, 28, 1063-1086.

Chamany, K., Allen, D., \& Tanner, K. (2008). Making biology learning relevant to students: Integrating people, history, and context into college biology teaching. CBE-Life Sciences Education, 7, 267-278.

Darner, R. (2007). The use of self-determination theory to foster environmental motivation in an environmental biology course (Doctoral dissertation). University of California, San Diego.

Darner, R. (2009). Self-determination theory as a guide to fostering environmental motivation. Journal of Environmental Education, 40, 39-49.

Darner, R. (2012). An empirical test of self-determination theory as a guide to fostering environmental motivation. Environmental Education Research, 18, 463-472. doi: 10.1080/13504622.2011.638739

Darner, R. (2014). Influences on students' environmental self determination and implications for science curricula. International Journal of Environmental and Science Education, 9(1), 21-39.

Deci, E. (1992). The relation of interest to the motivation of behavior: A selfdetermination theory perspective. In Renninger, K., Hidi, S., \& Krapp, A. (Eds.), The role of interest in learning and development. Hillsdale, $\mathrm{NJ}$ : Erlbaum.

Deci, E., \& Ryan, R. (1985). Intrinsic motivation and self-determination in human behavior. New York: Plenum.

Deci, E. L., Vallerand, R. J., Pelletier, L. G., \& Ryan, R. M. (1991). Motivation and education: The self-determination perspective. Educational Psychologist, 26(3-4), 325-345.

Dori, Y., Tal, R., \& Tsaushu, M. (2003). Teaching biotechnology through case studies: Can we improve higher-order thinking skills of non-science majors? Science Education, 87, 767-793.

Edelson, D., \& Joseph, D. (2004). The interest-driven learning design-framework: Motivating learning through usefulness. In Proceedings of the 6 th international conference on learning sciences (pp. 166-173). Santa Monica, CA: International Society of the Learning Sciences.

Gardner, G., \& Jones, G. (2011). Perceptions and practices: Biology graduate teaching assistants' framing of a controversial socioscientific issue. International Journal of Science Education, 33, 1031-1054. doi: 10.1080/09500691003743244

Glaser, B. G., \& Strauss, A. L. (1967). The discovery of grounded theory: Strategies for qualitative research. Chicago: Aldine.

Grolnick, W. S., \& Ryan, R. M. (1989). Parent styles associated with children's self-regulation and competence in school. Journal of Educational Psychology, 81, 143-154. doi: 10.1037/0022-0663.81.2.143

Guay, F., Ratelle, C. F., \& Chanal, J. (2008). Optimal learning in optimal contexts: The role of self-determination in education. Canadian Psychology, 49, 233-240. doi: 10.1037/a0012758

Guay, F., Vallerand, R., \& Blanchard, C. (2000). On the assessment of situational intrinsic and extrinsic motivation: The Situational Motivation Scale (SIMS). Motivation and Emotion, 24, 175-213.

Hall, K., Watkins, J., Coffey, J., Cooke, T. J., \& Redish, E. F. (2011). Examining the impact of student expectations on college-level curricular reform. In American educational research association 2011 annual meeting proceedings (New Orleans, LA).

Harris, R., \& Ratcliffe, M. (2005). Socio-scientific issues and the quality of exploratory talk-what can be learned from schools involved in a "collapsed day" project. Curriculum Journal, 16, 439-453.

Hewitt, K. M., Kayes, L. J., Hubert, D., \& Chouinard, A. (2014). Investigating issues in the laboratory: The behavior of red swamp crayfish as an invasive species. American Biology Teacher, 76, 609-614.

Hofstein, A., \& Lunetta, V. N. (2004). The laboratory in science education: Foundations for the twenty-first century. Science Education, 88, 28-54 doi: $10.1002 /$ sce.10106

Jarvela, S. (2001). Shifting research on motivation and cognition to an integrated approach on learning and motivation in context. In Volet, S., \& Jarvela, S. (Eds.), Motivation in learning contexts: Theoretical advances and methodological implications (pp. 1-13). Bingley, UK: Emerald Group.

Krippendorff, K. (1980). Content analysis: An introduction to its methodology. London: Sage.

Laugksch, R. (2000). Scientific literacy: A conceptual overview. Science Education, 84, 71-94.
Lee, M., \& Erdogan, I. (2007). The effect of science-technology-society teaching on students' attitudes toward science and certain aspects of creativity. International Journal of Science Education, 11, 1315-1327.

Lenz, L., \& Willcox, M. (2012). Issue-oriented science: Using socioscientific issues to engage biology students. American Biology Teacher, 74, 551556.

Levesque, C., Zuehlke, A. N., Stanek, L. R., \& Ryan, R. M. (2004). Autonomy and competence in German and American university students: A comparative study based on self-determination theory. Journal of Educational Psychology, 96, 68-84. doi: 10.1037/0022-0663.96.1.68

Liu, O. L., Lee, H.-S., Hofstetter, C., \& Linn, M. (2008). Assessing knowledge integration in science: Construct, measures, and evidence. Educational Assessment, 13, 33-55. doi: 10.1080/10627190801968224

Matsumura, L. C., Garnier, H. E., \& Spybrook, J. (2013). Literacy coaching to improve student reading achievement: A multi-level mediation model. Learning and Instruction, 25, 35-48. doi: 10.1016/j.learninstruc.2012.11.001

Namey, E., Guest, G., Thairu, L., \& Johnson, L. (2007). Handbook for teambased qualitative research. Lanham, MD: Rowman Altamira.

Parchmann, I., Grasel, C., Baer, A., Nentwig, P., Demuth, R., \& Ralle, B. (2006) "Chemie im kontext": A symbiotic implementation of a context-based teaching and learning approach. International Journal of Science Education, 28, 1041-1062.

Patton, M. Q. (2002). Qualitative research and evaluation methods (3rd ed.). Newbury Park, CA: Sage.

QSR International. (2012). NVivo10 [Computer Software]. Doncaster, Vic. Australia.

Ratelle, C. F., Guay, F., Vallerand, R. J., Larose, S., \& Senécal, C. (2007) Autonomous, controlled, and amotivated types of academic motivation: A person-oriented analysis. Journal of Educational Psychology, 99, 734746. doi: 10.1037/0022-0663.99.4.734

Raudenbush, S. W. (1997). Statistical analysis and optimal design for cluster randomized trials. Psychological Methods, 2, 173-185. doi: 10.1037/1082 989X.2.2.173

Raudenbush, S. W., \& Bryk, A. S. (2002). Hierarchical linear models: Application and data analysis methods. Thousand Oaks, CA: Sage.

Renninger, K. A. (1992). Individual interest and development: Implications for theory and practice. In Renninger, K., Hidi, S., \& Krapp, A. (Eds.), The role of interest in learning and development (pp. 361-395). Hillsdale, NJ: Erlbaum.

Ryan, R. M., \& Connell, J. P. (1989). Perceived locus of causality and internalization: Examining reasons for acting in two domains. Journal of Personality and Social Psychology, 57, 749-761. doi: 10.1037/0022 $-3514.57 .5 .749$

Ryan, R. M., \& Deci, E. L. (2000). Intrinsic and extrinsic motivations: Classic definition and new directions. Contemporary Educational Psychology, 25, 54-67. doi: 10.1006/ceps.1999.1020

Sadler, T. D. (2004). Informal reasoning regarding socioscientific issues: A critical review of research. Journal of Research in Science Teaching, 41, $513-536$.

Sadler, T. D. (2009). Situated learning in science education: Socio-scientific issues as contexts for practice. Studies in Science Education, 45, 1-42.

Sadler, T. D. (Ed.). (2011). Socio-scientific issues in the classroom: Teaching, learning and research. Dordrecht, Netherlands: Springer.

Sadler, T. D., Barab, S. A., \& Scott, B. (2007). What do students gain by engaging in socioscientific inquiry? Research in Science Education, 37, $371-391$.

SAS Institute (2008). SAS version 9.2 [Computer Software]. Cary, NC

Seymour, E., \& Hewitt, N. (1997). Talking about leaving: Why undergraduates leave the sciences. Boulder, Co: Westview.

Sheldon, K. M., \& Krieger, L. S. (2007). Understanding the negative effects of legal education on law students: A longitudinal test of self-determination theory. Personality \& Social Psychology Bulletin, 33, 883-897. doi: $10.1177 / 0146167207301014$

Standage, M., \& Treasure, D. C. (2002). Relationship among achievement goal orientations and multidimensional situational motivation in physical education. British Journal of Educational Psychology, 72, 87-103.

Vallerand, R. J. (1997). Toward a hierarchical model of intrinsic and extrinsic motivation. In Zanna, M. P. (Ed.), Advances in experimental social 
psychology (Vol. 29, pp. 271-360). San Diego, CA: Academic. doi 10.1016/S0065-2601(08)60019-2

Vallerand, R. J., Fortier, M. S., \& Guay, F. (1997). Self-determination and persistence in a real-life setting: Toward a motivational model of high school dropout. Journal of Personality and Social Psychology, 72, 1161-1176. doi: $10.1037 / 0022-3514.72 .5 .1161$

Vansteenkiste, M., Lens, W., \& Deci, E. L. (2006). Intrinsic versus extrinsic goal contents in self-determination theory: Another look at the quality of academic motivation. Educational Psychologist, 41, 19-31. doi: 10.1207/ s15326985ep4101_4

Weber, R. (1990). Quantitative applications in the social sciences: Basic content analysis. Thousand Oaks, CA: Sage. doi: 10.4135/9781412983488
Wicker, F. W., Turner, J. E., Reed, J. H., McCann, E. J., \& Do, S. L. (2004). Motivation when optimism declines: Data on temporal dynamics. Journal of Psychology, 138, 421-432. doi: 10.3200/JRLP.138.5.421-432

Yager, S., Lim, G., \& Yager, R. (2006). The advantages of an STS approach over a typical textbook dominated approach in middle school science. School Science and Mathematics, 106, 248-260.

Zeidler, D., Sadler, T., Applebaum, S., \& Callahan, B. (2009). Advancing reflective judgement through socio-scientific issues. Journal of Research in Science Teaching, 46, 74-101.

Zeidler, D. L., Sadler, T. D., Simmons, M. L., \& Howes, E. V. (2005). Beyond STS A researched-based framework for socioscientific issues education. Science Education, 89, 357-377. 